\title{
BISCOITOS TIPO AMANTEIGADO INCORPORADO COM FARINHA DE CAROÇO DE AÇAÍ
}

\section{Joelma Oliveira Souza ${ }^{1}$; Laís Maciel Rodrigues²; Thaís Souza Amorim³; Renato Souza Cruz ${ }^{4}$.}

1.Bolsista PIBIC/FAPESB, Graduando em Engenharia de Alimentos, Universidade Estadual de Feira de Santana, email: joelmasouzatst@gmail.com

2. Bolsista PIBIC/CNPq, Graduando em Engenharia de Alimentos, Universidade Estadual de Feira de Santana, email: sialmaciel@gmail.com

3. Mestranda, Universidade Federal da Bahia, e-mail: thaisouzamorim@gmail.com

4. Orientador, Departamento de Tecnologia, Universidade Estadual de Feira de Santana, e-mail: cruz.rs@gmail.com

PALAVRAS-CHAVE: subproduto agroindustrial, tecnologia, resíduo.

\section{INTRODUÇÃO}

Atualmente, a crescente preocupação com possíveis impactos ambientais e o elevado índice de perdas e desperdícios gerados pelas indústrias de alimentos tem levado pesquisadores a buscar alternativas viáveis de aproveitamento e geração de novos produtos com maior valor agregado para o consumo humano (PEREIRA, 2005). A utilização do caroço de açaí para fabricação de farinha pode ser uma ótima alternativa para a destinação deste material, promovendo o desenvolvimento sustentável. Podendo ser utilizado em complemento de biscoitos para aumentar o valor nutricional.

A utilização de farinhas mistas expandiu-se para a fabricação de biscoitos, já que esse produto, segundo VITTI et al.(1979), é aceito e consumido por pessoas de qualquer idade e possui poder atrativo. Com isso surgiu o interesse em fabricação de Biscoitos, por apresentarem também longa vida de prateleira e baixo custo. $\mathrm{O}$ produto com tais características, aliadas a sua enorme diversidade, revela-se um bom veículo para o estudo de farinhas mistas, seja por razões econômicas, seja por razões nutricionais. Neste contexto, a presente proposta visou obter condições de reaproveitamento do subproduto através da farinha de Caroço de Açaí na substituição parcialmente de farinha de trigo para a produção de biscoitos, avaliando e caracterizar os produtos com melhor aceitação quanto às características tecnológicas e nutricionais.

\section{METODOLOGIA}

A pesquisa foi desenvolvida nos Laboratórios de Engenharia de Alimentos da Universidade Estadual de Feira de Santana Ba.

\section{- Obtenção da Farinha de Caroço de Açaí (FCA)}

O caroço de Açaí foi obtido na Cidade de Bélem-Pará. Para obtenção da farinha de caroço de Açaí foi necessário a limpeza e higienização dos grãos que após essa etapa foram submetidos à secagem em secador de bandejas a temperatura de $50^{\circ} \mathrm{C}$ por três horas e depois de seco, foi triturado em moinho de faca utilizando peneira com abertura de 30 mesh.

\section{- Caracterização Fisico-quimica da FCA}

A umidade da farinha foi determinada por balança de infravermelho, com temperatura ajustada a $90^{\circ} \mathrm{C}$ e estabilização de 60 s. A análise de fibra total foi desenvolvida de acordo com metodologia descrita no INSTITUTO ADOLFO LUTZ (2008). Para 
determinação do tamanho das partículas da FCA foi utilizada a metodologia descrita por Cereda e Catâneo, 1986.

- Desenvolvimento do Biscoito tipo amanteigado incorporado com farinha de caroço de açaí

Os biscoitos com farinha de caroço de Açaí foram obtidos pela substituição ( 1, 5, 10 e $15) \%$ da farinha de trigo pela FCA, mantendo as mesmas condições de processamento. Para preparação da massa, utilizou-se 30\% de gordura, 25\% de açúcar, $20 \%$ de ovos e $0,5 \%$ de sal até a obtenção de uma massa homogênea. A massa foi laminada em molde de $0,8 \mathrm{~cm}$ de espessura e cortada em retângulos de $2 \mathrm{~cm}$ de largura, $0,8 \mathrm{~cm}$ de espessura e $9 \mathrm{~cm}$ de comprimento. Os biscoitos produzidos foram expostos ao forneamento à $180^{\circ}$ por 30 minutos conforme metodologia proposta pela AACC, 1999. Em seguida foram resfriados e acondicionados.

\section{- Características tecnológicas do biscoito}

As características tecnológicas dos biscoitos foram determinadas após 24 horas do forneamento de acordo com os procedimentos descritos no método 10-50 da AACC (1999).

\section{- Características de Textura do biscoito}

A dureza e a flexibilidade dos biscoitos foram avaliadas em texturômetro TA. XT.plus, utilizando-se o software Exponent Stable Micro Systems segundo metodologia descrita por Bourne, 1978.

\section{RESULTADOS E/OU DISCUSSÃO}

\section{- Caracterização Fisico-quimica da FCA}

A farinha do caroço de açaí apresentou um teor $9,88 \pm 0,0424 \%$ de umidade dentro do limite estabelecido pela legislação e um elevado percentual de fibra alimentar, confirmando seu potencial para utilização como ingrediente em formulações de diversos produtos com o objetivo de promover benefícios à saúde. A FCA apresentou uma maior quantidade de massa retida cerca de 57,48\% em uma peneira de 60 mesh e $28,03 \%$ em peneira de 42 mesh. Portanto a granulometria da farinha é maior que 60 mesh, fornecendo ao produto final um aspecto granular decorrente de um processo de trituração assimétrico.

\section{- Características tecnológicas do biscoito}

A Tabela 1 apresenta os modelos significativos $(\mathrm{p}<0,05)$ para as avaliações físicas dos biscoitos, como índice de expansão e espessura, perda de peso e massa específica.

Com o aumento da concentração da farinha de caroço de açaí o índice de expansão diminuiu enquanto que o índice de espessura aumentou. Esses índices têm sido utilizados como indicadores de qualidade dos produtos. Segundo Perez e Germani (2007), o fenômeno de expansão de biscoitos é primariamente físico e está relacionado com a capacidade dos ingredientes em absorver água, como a farinha. Assim o acréscimo de componentes que possuem maior capacidade para reter água do que a farinha de trigo resulta em uma competição pela água livre presente na massa do biscoito limitando a taxa de expansão. Geralmente biscoitos elaborados com alto teor de 
fibras apresentam diminuição do fator de expansão (ASSIS et al., 2009; PEREZ; GERMANI, 2007; SILVA et al., 2001).

Pode observar pela tabela 1, que houve uma ligeira perda de peso e um ligeiro aumento da massa específica com a adição da farinha de caroço de açaí. Esse fato deve ser relacionado com a maior quantidade de água absorvida na presença da farinha de caroço de açaí, que no assamento é evaporada justificando a diminuição da perda de massa.

Tabela 1. Modelos preditivos para avaliações físicas dos biscoitos elaborados com diferentes concentrações $(1,5,10$ e $15 \%)$ de farinha de caroço de açaí além da padrão $(0 \%$ FCA $)$

\begin{tabular}{ccc}
\hline Parâmetros & Modelos & $\mathrm{R}^{2}$ \\
\hline índice de Expansão $(\mathrm{cm})$ & IndExp $=-0,0122[\mathrm{FCA}]+1,1437$ & 0,8245 \\
Índice Espessura $(\mathrm{cm})$ & IndEsp $=0,0018[\mathrm{FCA}]+0,8916$ & 0,8633 \\
Perda de Peso $(\mathrm{g})$ & PerdaP $=0,0028[\mathrm{FCA}]+0,1319$ & 0,9909 \\
Massa Específica $(\mathrm{g})$ & MassaEsp $=-0,0041[\mathrm{FCA}]+0,7956$ & 0,9561 \\
\hline
\end{tabular}

*IndExp, índice de expansão; IndEsp, índice de Espessura; PerdaP, perda de peso; MassaEsp, massa específica

\section{- Características de Textura do biscoito}

De acordo com a análise de textura, a dureza dos biscoitos apresentou um ponto de máximo em $5,44 \%$, enquanto que a fraturabilidade apresentou um ponto de mínimo em $4,07 \%$ isso significa que valores maiores que esses são favoráveis a qualidade do biscoito, segundo (ASSIS et al., 2009). A adição da FCA provocou a diluição das proteínas do glúten levando ao enfraquecimento da rede traduzindo em diminuição da dureza. Por outro lado, a grande quantidade de fibra encontrada na FCA fez com que a fraturabilidade aumentasse, pela mesma razão da diminuição da dureza, o enfraquecimento da rede de glúten pela presença das fibras. As proteínas do glúten formam uma rede contínua dentro da massa, durante a mistura da farinha de trigo e dos outros ingredientes, sendo assim, as propriedades do glúten em particular têm um impacto sobre o produto final.

Diante do modelo apresentado para o parâmetro dureza foi feita a predição da concentração de FCA ideal, ou seja que se assemelhasse à formulação padrão, chegando ao resultado de 8,5\%. Assim, uma formulação com 8,5\% de FCA foi elaborada e avaliada quanto a textura. O resultado indica que houve diferença significativa $(\mathrm{p}<0,05)$ para os parâmetros dureza e fraturabilidade entre a formulação padrão $(0 \%)$ e a predita $(8,5 \%)$, onde as médias para dureza foram F8,5 $=1574,72 \pm 117,44$ e $\mathrm{F} 0=$ $3494,00 \pm 368,39$ e para fraturabilidade $\mathrm{F} 8,5=0,92 \pm 0,06$ e $\mathrm{F} 0=0,68 \pm 0,02$.

\section{CONSIDERAÇÕES FINAIS}

Os resultados obtidos nesta pesquisa indicaram viabilidade na produção do biscoito com substituição parcial da farinha de trigo pela farinha de caroço de açaí, sob o ponto de vista tecnológico e nutricional.

A farinha do caroço de açaí apresentou um teor de umidade dentro do limite estabelecido pela legislação e um elevado percentual de fibra alimentar, confirmando 
seu potencial para utilização como ingrediente em formulações de diversos produtos com o objetivo de promover melhoramento nutricional.

A partir das análises tecnológicas do biscoito, percebe-se que com o aumento da concentração da farinha de caroço de açaí o índice de expansão diminui enquanto que o índice de espessura aumenta. Havendo também uma ligeira perda de peso e um ligeiro aumento da massa específica. Através da análise de textura foi possível obter uma formulação ideal, com 8,5\% de farinha de caroço de açaí, que mais se aproximou dos parâmetros de dureza e fraturabilidade da formulação padrão.

Assim, a pesquisa demonstrou o potencial de reaproveitamento do caroço de açaí como farinha, constituindo uma nova proposta para a utilização em biscoitos e o desenvolvimento de alternativas alimentícias.

\section{REFERÊNCIAS}

AACC - American Association Of Cereal Chemists. Approved methods of the AACC.8 ed.Saint Paul: AACC, 1999.

INSTITUTO ADOLFO LUTZ. Procedimentos e Determinações Gerais: Métodos Químicos e Físicos para Análise de Alimentos. 1.ed. digital. São Paulo: Instituto Adolfo Lutz, 2008.

BOURNE, M. C. Texture profile analysis. Food Technol., v.7, n. 32, p. 62- 66, 1978.

COSTA, M.R.; OLIVEIRA, M.S.P.; MIURA, E.F. Variabilidade genética em açaizeiro (Euterpe oleraceae Mart.). Biotecnologia Ciência e Desenvolvimento, Brasília, v. 4, n.21, p.46-50, 2001.

MARCELINO, J. S; MARCELINO, M.M. DOSSIÊ TÉCNICO- Fabricação de Bolachas e Biscoitos. Instituto de Tecnologia do Paraná, Julho 2012.

MORAES, K. S.; ZAVAREZE, E. R.; MIRANDA, M. Z.; SALASMELLADOMORAES, M. M. Avaliação tecnológica de biscoitos tipo cookie com variações nos teores de lipídio e de açúcar. Ciênc. Tecnol. Aliment., Campinas, 30(Supl.1): 233-242, maio 2010.

LIMA, H. T; Aproveitamento de Resíduos Agroindustriais (Borra de Açaí e Glicerol) na Elaboração de Biscoito. Universidade Federal do Pará Instituto de Tecnologia Programa de Pós-Graduação em Ciência e Tecnologia de Alimentos, Belém-Pa, 2009.

OLIVEIRA, M.E.; CLERICI, M.T.P.S. Qualidade física, química e sensorial de biscoitos tipo cookies elaborados com a substituição parcial da farinha de trigo por farinha desengordurada de gergelim. Universidade Federal de Alfenas (UNIFALMG) Departamento de Nutrição Alfenas/MG - Brasil.

PEREIRA, C. A.; CARLI, L.; BEUX, S.; SANTOS, M. S.; BUSATO, S. B.; KOBELNIK, M.; BARANA, A. C. Utilização de farinha obtida a partir de rejeito de batata na elaboração de biscoitos. Universidade Federal de Ponta Grossa. Centro de Ciências Exatas Terra, Ponta Grossa, v.11, n.1, p.19-26, abril, 2005.

PEREZ, P. M. P.; GERMANI, R. Elaboração de biscoitos tipo salgado, com alto teor de fibra alimentar, utilizando farinha de berinjela (Solanum melongena, L.). Ciência e Tecnologia de Alimentos, Campinas, v. 27, n. 1, p.186-192. 2007. 